\title{
A Story of Great Expectations: Past and Present of Online/Virtual Exhibitions
}

\author{
Cèsar Carreras* and Federica Mancini** \\ *Department of Antiquity, Autonomous University of Barcelona (UAB), Civic Square, Bellaterra, Cerdanyola, Spain \\ E-mail: ccarreras@uoc.edu
}

**Universitat Oberta de Catalunya, (UOC) Av. Tibidabo, 39-43 Barcelona, Spain

E-mail: federicamancini3@gmail.com

\begin{abstract}
The present paper attempts to discuss the practices of virtual exhibitions covering topics that were not taken into account a decade ago. Topics such as the effort involved in creating an online exhibition, which also affects the time, costs and human resources that are not always available in memory institutions of middle and small size. The best online exhibitions that enjoy international awards demand a high budget only available to large institutions. Therefore, are they good models for the remaining cultural institutions? Another issue is the degree of complementarity between a real and virtual exhibit and fears of competition. Most memory institutions prefer to create their online exhibits once the temporary exhibition is finished. Virtual exhibitions become records of museum activities that are no longer in place. Public participation in content creating was also a wish a decade ago, but new tools have facilitated such cooperation. Both behaviours generate virtual communities (local or distant) around the cultural institution, which is one of the aim of the current development of web 2.0. Of course, technical developments in IT have modified forms and possibilities of current exhibitions (i.e., virtual worlds, video, animations, XML, mobile phones) that should be tested to overcome some of previous drawbacks. The use of participatory technologies in some cases has led not only to bring nearer the museum to its audiences, but rather to subvert the traditional unidirectional relationship between them. This paper combines theoretical discussions of such topics with some empirical data obtained for more than ten years of developing and analysing virtual exhibitions.
\end{abstract}

Keywords: Virtual exhibitions, Catalan immigration, flash technology, museums, maps

\section{INTRODUCTION}

Virtual exhibitions are new potential applications for cultural institutions that pretend to disseminate contents of one of their most creative products: a temporal exhibit. So far not many institutions have been making much effort in creating virtual exhibitions, since they have not foreseen potential outputs. Experiences from the late 90's up to now demonstrate that a virtual exhibit is always a worthwhile investment, because it is an excellent presentation for any institution and gives new life to contents, which are hidden in catalogues.

Almost a decade has passed by since first virtual exhibition was started. It was the time when IT appeared to solve some of the problems of dissemination and marketing of the most attractive cultural products of museums and memory institutions: temporary exhibitions. In 2001, A paper ${ }^{1}$ based on authors first experiences foreseeing great expectations for the online exhibitions as well as the fears from curators, who believed that virtual exhibits could get visitors apart from the museums was published.
At that time, virtual exhibitions were expected to complement real exhibitions in terms of content, to encourage visitors to come to real exhibits (marketing), to recreate virtual worlds costless? In real environments, to give access to new audiences, to provide basic content background for real exhibits and to become a fix resource when temporary exhibitions were dismantled. At present, only some of those expectations have been completely fulfilled and real practices have changed a little from those idealistic views.

Moreover, now more data are available about how and who is using those online exhibitions (i.e., educational contexts, tourism, digital archives), which require further reflection. They encourage visitors to actively participate in the exhibits with the help of special mobile phone cameras that record their journeys through the exhibition and instantly upload them on the museum's website. A number of institutions have contributed to reduce the conventional separation between real and virtual worlds. 


\section{ONLINE-VIRTUAL EXHIBITIONS: LATE 90'S}

The coming of world wide web (www) and internet in the mid 90's brought about many potential applications of this technology into a myriad of fields and professional sectors. One of them is memory institution (museums, libraries, and archives), which generated great expectations about the potential of such a new media because of their dissemination power, which could widen the visitors and service users of the particular institution.

Temporary exhibits are one of the most outstanding activities of memory institutions, but require much effort in economic and intellectual terms, and hardly provide enough material return. Only few cases can be shared with other institutions which have similar conditions in the exhibition halls and objects can be easily borrowed. However, most exhibitions have a short-life despite its important creative investment and sometimes they only remain as a memory in form of a well-published catalogue or CD-ROM/DVD.

With the advent of www in the mid 90's, many curators, librarians, and archivists thought that these could be an excellent alternative to keep those temporary exhibitions alive. In fact, most of them regarded the tool as a post-exhibition application, a way to give universal access to a temporary event that was no longer in place. First effort in virtual exhibitions was a temporary exhibit in 1999 called 'Always Ibiza and Formentera'2, which pretended to show a different view of the local tradition of two Balearic Islands (Spain) that international tourism was systematically forgetting. The temporary exhibit was a local initiative attempting to preserve the way local people wanted to keep these two islands. However, the temporary exhibition was only presented at five different venues in the Balearic Islands and Barcelona in the winter season, so not many potential visitors could easily access it. This is why a virtual exhibition was envisaged as a way to disseminate the information to tourists coming to see the islands and understand local traditions.

The virtual exhibition was a success, mainly in English version because it was used by foreign travel agencies. It was complementary to the real exhibition because it included more images and text, and a virtual reconstruction (3D model) of what was expected to be a fix venue for this exhibition. It was realised from this early experience that virtual exhibits have a lot of potential with a minimum extra investment. With regard to its lasting life, this virtual exhibit, still online (spring 2009 - ten years later), receives at the present $1400 / 1700$ visits a month from at least 10 countries like Spain, USA, Great Britain, Japan, Netherlands, Canada, France, and Germany. Therefore, virtual exhibits have a long-lasting life or value which is admired and appreciated by everyone.

The study of logins to this resource as well as questionnaires with specialists and focus groups ${ }^{2}$ revealed that virtual exhibits were used in a different way than a presential exhibit. Virtual visitors tend to access only small parts of the resource like an archive of multimedia contents (i.e., text, images, audio, and video) perhaps to reuse it in another context. A small percentage of virtual visitors undertook a full visit of the virtual exhibit, whereas most users came with educational or tourist interests. In other words, virtual exhibits are used in different contexts and forms than the ones in which they were initially created.

According to a survey carried out by Dutardre ${ }^{3}$ for the Direction of French Museums, it was observed that people prefer complementarities between real and virtual museum. In most cases, they browsed websites looking for present and past exhibits and made a virtual tour within collections due to curiosity and desire for discovery and knowledge.

A second project taken in 2000 was the digitisation of an exhibition about books' illustrations - 'Aureum Opus: five centuries of illustrated books'4, which introduced two new challenges. According to the organisers, at the Frederic Mares Museum of Barcelona, the idea was that the virtual exhibit should encourage people to come to visit the real exhibit also Therefore, timing was a key issue since both the exhibits, real and virtual, needed to open at the same time. This generated an overstress in the whole project since organisers did not think that virtual exhibitions could require an extra effort to create new complementary contents and translations. In the end, managed to make the virtual exhibit accessible on time, but it was observed that not many people are persuaded by virtual exhibits to come to visit the real one: by the time, the virtual exhibit is well-known the temporary exhibit is already changing venue or is dismantled. Therefore, right timing did not encourage new visitors to visit the physical museum.

A later study ${ }^{5}$ revealed that many foreign visitors showed a willingness to see the real exhibit that they had seen on internet. However, by the time they discovered it, the exhibition was already over.

Another challenging issue of this exhibit was content creation and taking advantage of digital environments to provide alternative views to the objects and exhibition narratives. In this case, old books were presented in the real exhibition in showcases so that they could not be touched and browsed despite the fact that the main subject of the exhibition was book illustration. This is why most illustrations were scanned and presented in 
the online exhibition providing a full accessibility to the collection. Similarly, other exhibits which include old books, manuscripts or delicate objects are also available online.

Since the value of old books' illustrations depend on techniques employed in the past, most of our complementary content aimed at explaining techniques such as xylography, chalcography or lithography, and a 3D reconstruction in QuickTime of a possible engraver workshop. This background knowledge has been quite useful for virtual visitors, who have appreciated this basic information to understand the collection. Actually, a constructivist educational approach lies behind this idea of providing basic information to link general and specialised knowledge ${ }^{6}$. Only media changes here, as it happened in the past with audiovisual and TV communication media ${ }^{7,8}$, though Internet may suppose a more rooted shift.

A background or personalised information allows users to fully enjoy the real as well as the virtual visit. Questionnaires on visitors' opinions show that this is one aspect that they really appreciate ${ }^{5}$. Exhibitions are no longer for specialists, but anyone can fully appreciate them. In terms of visitors, nowadays the exhibition still receives an average of 5000 users a month from more than 20 countries. The presence of several images and old illustrations makes this virtual resource very popular as a graphic archive.

Other online exhibits created in 2000 shared the same features although subjects were slightly different. For instance, "Will you write me a letter?" deals with the subject of communication through correspondence from the origin of writing to e-mail with special stories between famous people and special cases such as war letters or prisoners' letters. From the technological point of view, a virtual environment (QuickTime VR) was developed to navigate through different sections as an alternative to the typical structured menu. From users' comments it appeared that the virtual navigation became so complex that most visitors chose the traditional navigation through menus. Yet, the most popular virtual exhibitions were fully using virtual environments such as 'Virtual Leonardo'10, which won the award the Best of the Web in 2000 as best online exhibition.

The success of exhibition about epistolary was limited because there was only a version in the local language-Catalan. This is a good lesson for the online exhibitions: only the major languages (English or Spanish to less extent) make an online resource really global for any visitor all over the world.

The last exhibit of 2000 was 'Treasures of Nature'11, a selection of 100 objects from the Natural Science Museum of Barcelona that reflect research and researchers in the field of natural sciences. It was an object-oriented exhibition complemented with more multimedia documentation in its virtual version as well background or personalised information for the diverse audiences that could access it. One of the main differences of this exhibit was its dissemination, since it was focused on educators and schools apart from the general public. One of the main surprises was that the virtual resource was employed in formal educational contexts, therefore giving a second life to the display.

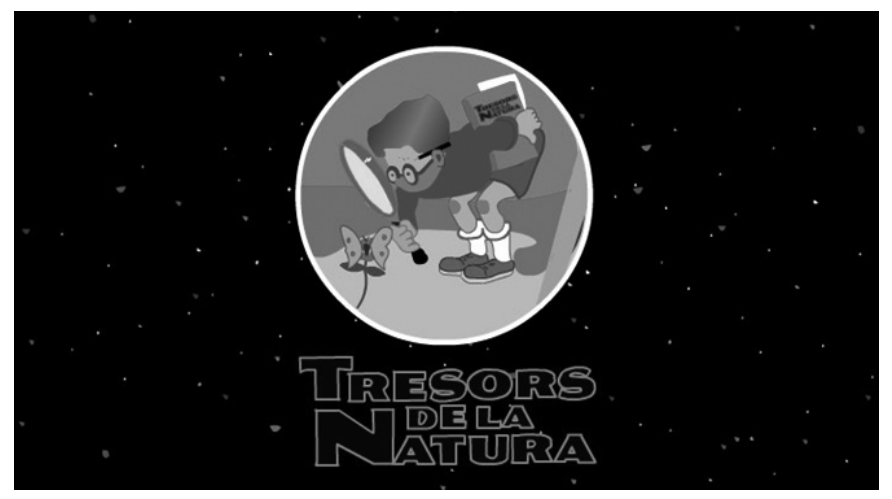

Figure 1. Home page of 'Treasures of Nature'11.

\section{FLASH TECHNOLOGY AND COMPLEXITY}

The Flash technology created a major revolution in online exhibitions and a more demanding effort in terms of cost and human resources for memory institutions. This increase in budget also generated a big gap between small/middle and large size institutions, since only the last ones could afford to create regularly high quality online displays.

In the late 90's new multimedia formats came into existence, such as audio and streaming video, live web casts, quizzes and games (edutainment). The website of the Tech Museum of Innovation in the 'Robotics: Sensing, Thinking, Acting' already offered in 2000 both video on demand and streaming (live webcast), the latter being more complex to produce and manage. Also the Holocaust Memorial Museum (USA) developed during the same period with different interactive solutions for their users, choosing the Flash Communications Server (Flashcom) software as its technology for webcasts. The virtual tour was made up of online galleries representing the real exhibitions. Curators' comments on video and audio, made some sort of soundtrack while browsing. Interested visitors could also chat in real time with historians available at that time. Comments and interesting questions were then stored online in a database used by the public and shaping a sort of a container of the key issues that users could explore to enrich their knowledge about the Holocaust.

Besides, these initial years also represented a new pattern of exhibitions based on peoples' stories. A kind of emotional displays (Hearts-on) in which 
visitors could identify themselves with anonymous characters as it happens in the cinema. These displays were normally tragic experiences such as war, holocaust or immigration, which also allowed virtual visitors to take part by including their own experiences (precedent of web 2.0 philosophy).

An early experience was the Exploratorium exhibition in 1999 'Remembering Nagasaki'12 about the first nuclear bombing and results of such tragedy in Japanese lives. There was an open section that allowed visitors to explain their experiences, so many Japanese relatives of the victims revealed a completely different view that the Americans had. The experience was so enriching that became a model for later exhibits. Therefore, it is not strange that the winner of the Best award of the Web 2002 was an exhibition on the Croatian holocaust at 'Jasenovac $1941-1945^{\prime 13}$ by the Holocaust Museum (Washington). Using flash technology and be high quality images, the online display included touchy testimonies and oral stories of this historic drama, which reminded the contemporaneous Balkan conflicts.

In 2003, the authors were also involved in such a kind of hearts-on exhibition, which became quite rewarding in personal terms (The same year we produced an on-line exhibition called 'Images of stone: the Tunisian mosaics'14 which displayed a selection of quality Roman mosaics discovered in this country. The online exhibit attempted to explain complementary information about mosaic techniques, iconography, mosaic schools and same examples of different parts of the Roman Empire. It included a $3 \mathrm{D}$ reconstruction with Shockwave 3D of the Roman villa of Els Munts (Tarragona, Spain). It was an online version of a temporary itinerant exhibition about the Spanish Civil War (1936-1939) 'Memories of our childhood: The war children'15, still a taboo subject in contemporary Spain. However, the virtual version changed completely its structure, since it was believed that the most attractive part were the testimonies of those former children that were now old people. It was decided to see the whole war conflict through the eyes of children who left their families to become refugees all over the world (Great

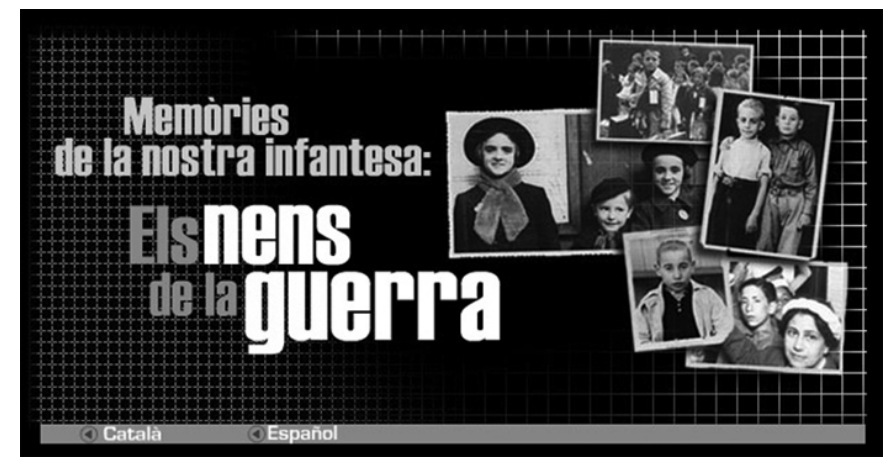

Figure 2. Home page of 'Memories of our childhood: The war children'15.
Britain, France, Mexico, Belgium, Russia, Argentina...) and who sometimes never came back.

The personal life stories were so touchy and had a lot of impact on the public. We received messages of people crying to see the images, identifying some of their loved ones and asking for copies of films and photographs. For many of these refugee children living in Argentina, Mexico or France it was the first time that they could remember their own story. The authors received a Yahoo prize in cultural webs in 2003. Despite being in only two languages (Catalan and Spanish), it still enjoys a big popularity, with more than 1500 visitors a month from more than 10 countries including USA, European and Asian countries. For a long time, this resource has been used in secondary schools to teach students about the Civil War through the eyes of testimonies of their same age.

Like in the case of 'Remembering Nagasaki', we created a section in which virtual testimonies could record their own story, and in fact many people still keep introducing new stories and comments until now (again a precedent of web 2.0). Another distinctive feature was connectioning past testimonies with present ones keeping the same exhibition structure from other war contemporary conflicts in which children are also victims.

Introducing flash technology normally meant for creating a more complex online exhibition, which involved a team of multimedia developers from private companies or collaboration with ICT institutions such as universities. Some large institutions have invested part of their budget to produce high quality products such as the Best of the Web winners, while others developed strategies for low-cost exhibitions taking advantage of database formularies.

For instance, the Best of the Winner as online exhibitions in 2003 was 'Corridos sin Fronteras'16, a high quality flash website with an important budget created by the Smithsonian, which explained the Mexican history from its 'corridos' songs. It played with audio files from a timeline, which was an innovative application at that moment. There were also educational applications that allowed users to create their own lyrics from a standard corridos song.

An alternative way was the so-called 'exhiblet' from the Science Museum of London ${ }^{17}$, that attempted to create online exhibits from the temporary exhibition but at a very low cost. Multimedia contents used in the real exhibition were stored in a database (basically images and text), and then downloaded with the appropriate format in a website. The idea was to make available contents of all activities of the institution at a very low cost and in little time. Of course, those resources normally lack a story and special treatment regarding the type of virtual visitor that can access them. 
Similarly, in 2004 a collaborative work with the Catalan Immigration History Museum ${ }^{18}$, a small institution with limited funding that wished to promote its temporary exhibitions was done and a series of HTML templates were created for easily downloading images and texts from the real exhibitions in order to generate an online resource.

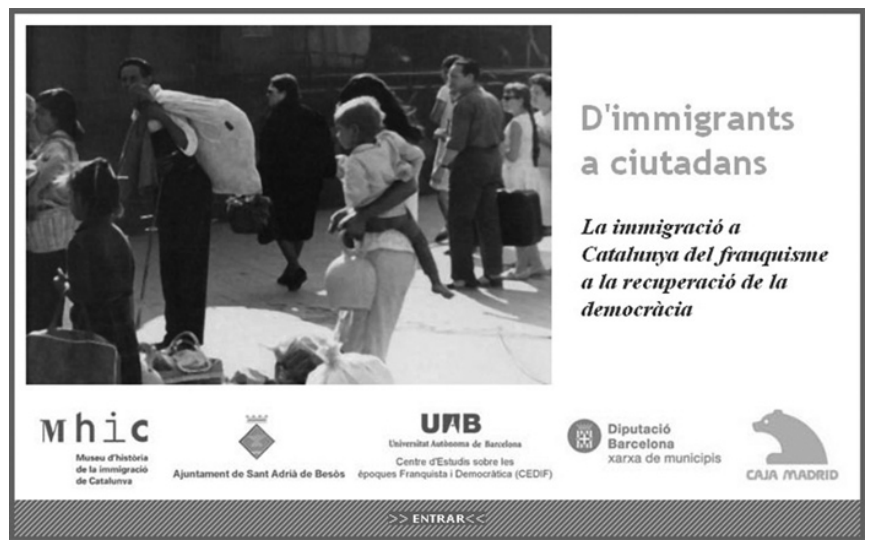

Figure 3. Online exhibit from the Catalan Immigration History Museum.

Those online exhibits were rather simple with a hierarchical menu on the left, a group of images or other multimedia, and the main body of text. It was a way to publish raw documentation from an exhibition, but not a format that took advantage of all the potential of cybermuseography (internet museography).

A more technical approach was employed for the 'Voices' exhibition in 2004'19, in which flash technology; audio and video files were employed to create capsules of content. Every application identified a concept or idea related to the exhibition. There were special applications and itineraries for children.

\section{REAL AND VIRTUAL: NEW COMPLEMENTARITIES}

With new technological innovations, online exhibitions have been enriched with multiple media formats, which make virtual presentations more engaging. They have also contributed to overcome the idea that the online exhibition was just a competitive replica of the real one. Some of the studies carried out in recent years have indeed contributed to dissolve the initial reluctance of some professionals of the field towards the virtual exhibitions. According to the survey conducted by Statistics Canada for the Canadian Heritage Information Network, the more people visit the virtual museum the greater will be the probability they will also decide to come to the real one ${ }^{20}$.

Virtual exhibitions seem to generate some benefits because they contribute to convey the power of physical exhibits to those who cannot visit personally, as well as to offer a closer interaction with artifacts through the use of web-based technologies. The Dutardre's investigation ${ }^{3}$ comes to the conclusion that most internet users access the museum website because they do not have a chance to visit the real museum and exhibitions.

The exhibition 'Woman of Letters-Irene Nemirovsky and Suite Francaise'21 organised by the Museum of Jewish Heritage of Manhattan shows lot of advantages that an online exhibition can bring to the real one, enhancing significantly the in-person experience and creating an intimate view of the author's life for those viewers who do not visit the physical exhibition.

Similarly, the Moma in collaboration with the Behaviour Design succeeded in representing the expressive force of the works displayed in its exhibitions by using flash technology. The exhibitions 'Georges Seurat: The Drawings'22 on display from October 2007 to January 2008, and 'Kirchner and the Berlin Street'23 on show from August to November 2008 acn be cited. In these websites, visual language and interactive design were used to convey contents.

In both cases, the exhibitions use flash technology and allow visitors to explore some interactive sketchbooks left by the authors and digitised by the museum, where visitors can view notes and drawings by turning the pages and zooming to details with a simple click. Through the manipulation of these sketchbooks, users are allowed to browse the sketches of Ernst Ludwig Kirchners' renowned Street Scenes series, created between 1913 and 1915, and Georges Seurat's beautiful drawings balancing between light and shadow. Choreographic elements and the intuitive interface gracefully reveal the artwork and invite users to marvel and explore at will.

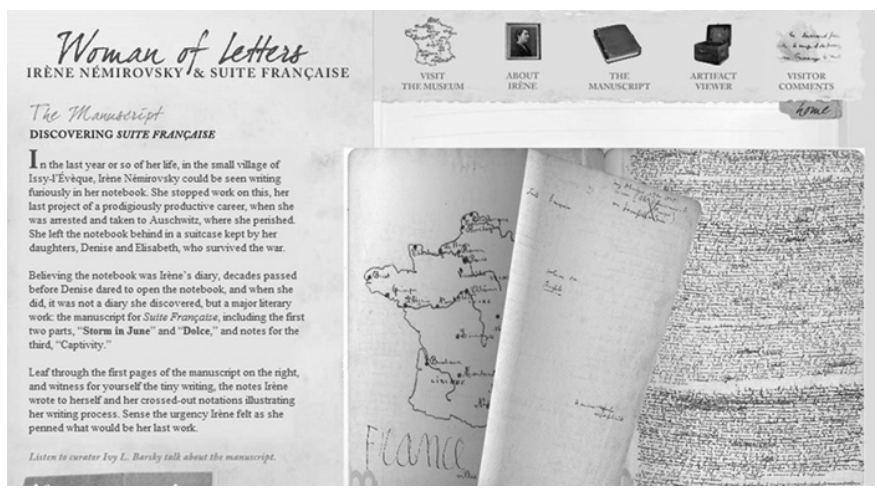

Figure 4. Online exhibit using interactive sketchbooks.

Technological advances have allowed museums to tell more and more complex stories, immersive through high-end sites. However, we are witnessing movements towards content syndication which separate content from design in order to secure a faster dissemination through blogs, podcasts, 
vodcasts, YouTube, Flickr, Drupal, SlideShowPro, SoundSlides, RSS and other database-driven sites. This is primarily due to independent producers of web content who have benefited from the use of applications easy-to-use to distribute their content. This produces an interesting phenomenon, i.e., the web content becomes a multimedia archive. Visitors access contents in the virtual exhibit through search engines instead of taking a formal virtual visit. In terms of login data, this system generates a short visit of all the viewers in less than a minute.

\section{PARTICIPATORY TECHNOLOGIES: CHALLENGES AND OPPORTUNITIES FOR MUSEUMS}

During the last years internet has changed, allowing anyone to upload images, video and audio files as well as to create and publish exhibitions, and to connect with other users within a virtual environment.

Initially, curators were interested in creating open source exhibitions that allowed them to update contents in the following months. Some of those 'under construction' exhibits required a technical interface that was simple enough for anyone to update contents and files. This is why CMS (content management systems) were introduced not only for managing institutions portals, but also for running virtual exhibitions. The exhibit 'Pictures from Traiguera'24, a history of a small community from magazine photographs, is managed by a local collaborator who administers an image database with textual formularies.

Nowadays, some open source CMS such as Joomla $1.5 !^{25}$ are being used to create virtual exhibits that can be updated both by creators and visitors. Some web 2.0 tools are also included in this new generation of CMS for setting up low cost virtual exhibitions. One example is virtual exhibit about the DNA $^{26}$ created for educational purposes combining Joomla 1.5! and some flash applications.

Around 2003-2004, cultural websites start talking about web 2.0. A paper from the Victoria \& Albert Museum entitled 'Learning From Amazon and eBay: User-Generated Material for Museum Web Sites'27 peeps the word user-generated content to describe the content produced by users. Although this concept seems to challenge the traditional role of curators and mediators, technologies 2.0 associated with web do not necessarily constitute a problem for the conventional museum, but rather offer many opportunities. The advantages detected until now regarding their use in virtual exhibitions are:

(a) Ability to capture new audience or retain the old one.

(b) Possibility to evaluate the success or failure of the exhibition and the audience's preferences, (c) Capacity to promote events and initiatives at low cost and to develop vital marketing phenomena, and

(d) Benefits of exploiting the educational potential of the constructivist learning model through collaboration and online dialogue.

Apart from helping museums to obtain a greater visibility, the use of web 2.0 applications seems to attract a higher number of visitors to the virtual space.

It is evident that the audiences, now fully used to move within the internet, often look at other visitor's comments to decide whether to visit an exhibition or not. This basically happens for one reason: people trust more their peers' than institutional voices. It is very likely that the comments of users are sincere.

A study involving the audience of the Museum di Arte Moderna e Contemporanea (Mart) to analyse users' practices in the museum's virtual space shows that more than a quarter of the (10) users out of the total (36) interviewed told that they got influenced to visit the real exhibition with the help of the information provided by other users. This shows that the adoption of a participatory philosophy and the use of appropriate tools can offer a real added value to the public that undertake a visit to the real exhibition.

The museums that have embraced a philosophy of participation have also the possibility to use the network to monitor the dialogue between users getting feedback and responses about their exhibitions. Similarly, monitoring posted photos on Flickr or videos on 'You Tube' can be very useful to understand which exhibits mainly impressed the visitors, to help replicate these for displaying in future occasions.

The case of the exhibition 'Graffiti', carried out by the Brooklyn Museum, opens new strategies for exhibition dissemination by using sites such as Flickr and MySpace to highlight the exhibition as well as, its in-gallery and online interactive projects. Thanks to a local street artist who is very popular in MySpace participated in the exhibition, in addition that the museum's staff were able to attract many users through a good word-of-mouth that contributed to promote the gallery, the podcasts and the other initiatives within the group of virtual friends. Therefore, the initiative allowed greater participation by joining two audiences: Web 2.0 community and the one from Brooklyn Museum's web. User participation generated also the firstever Museum archive of local street artist ${ }^{28}$ through which the museum had the opportunity to attract many more visitors to its virtual space.

Finally, with the aim of stimulating public participation in the exhibition, the museum provided to virtual 
visitors an online drawing tool created in 2005 for the exhibition 'Basquiat' through which visitors at the Graffiti exhibition page could create their own virtual graffiti by using virtual spray and other drawing tools. The positive results from such experience demonstrate that creating a virtual community does not mean necessarily to produce new contents for the web itself, but rather to capture audiences in communities from other sites as well as readapt old tools for new exhibitions.

In all cases, any well-designed content about an exhibition created by the community should encourage users to focus discussions: the same dialogue visitors may have in front of an exhibition at the museum could be established by users of an online content of the virtual space. However, as stated by Mitchell ${ }^{29}$, communities must still find ways to provide and maintain places of get-together for their members, whether these places are virtual, or physical, or a combination of the two: if these places are to serve their purposes successfully, and they may allow both freedom of access and freedom of expression.

Likewise, the exhibition 'Take Your Time'30 of the contemporary artist Olafur Eliasson, staged in 2008 at MOMA, lifted a long internal debate about the legitimacy of removing content considered not relevant to the theme of the exhibition. In this case the event's goal was testing new ways to encourage participation. The initiative, conducted by the Scandinavian artist, intended to encourage visitors to describe and comment his work without the museum's interference ${ }^{31}$ through an environment designed by 'SFMOMA new media group' where they could give expansion to their views. The interactive kiosk/website offered background commentaries and information about the artist's philosophy but left to the visitors the description of the individual works in detail of which each of them have a personal experience of the show. The traditional presentation of the exhibition in internet was therefore replaced by a customised WordPress blog.

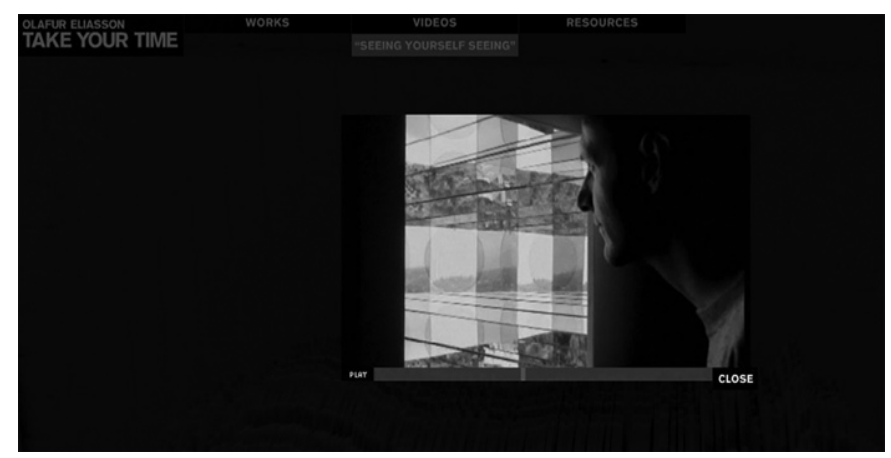

Figure 5. Video about the website showing the installation 'seeing yourself see' undertaken by Olafur Eliasson.
Despite the efforts of professionals to achieve their objectives by making the best use of the technology, only the options that respond to the user's needs will consolidate themselves ${ }^{32}$. These needs can lead the audiences to use technological applications in a different way than they were originally conceived. Hence, it is recommended that memory institutions undertake new ways of assessing the impact of technology on their virtual visitors by choosing qualitative methodologies besides the quantitative ones ${ }^{33}$.

\section{INTERACTIVE MAPS: A NEW TYPE OF ONLINE EXHIBITION?}

With the introduction of Earth representation software (Google Earth, MSN Live Search, Yahoo maps, etc.) new virtual public spaces began to spread. In these geographical environments, people can make virtual trips and discover new ways to access information or objects. More and more institutions are experimenting with this opportunity by launching initiatives where the activity of geotagging is at the core of their proposals.

Public participation in publishing geo-referenced information through latitude and longitude coordinates seem to offer a new way of organising content, which is clearer and more attractive for the visitor. An example of this technology can be seen at the exhibition '1620-1800-Style in the Age of Magnificence', in which under the heading of 'Global Interactive Baroque' 34 users can add their own images of baroque style objects in the Google map, uploading them first in Flickr, then adding references in the map and finally sharing the photos with the $V \& A$ group.

Geotagging also may help users find a huge variety of location-specific information looking for images by entering the coordinates into a Geotaggingenabled image search engine. In addition to this, this kind of system can potentially be used to find location-based links, information and other kind of resources. Some interesting cultural activities of geo-content are being developed within blogs. The birth of the geoblog is the core the concept of social net-working: creation, communication and the weave of relations. The geoblog is a collaborative platform because it is shared and stimulates the collaboration not only between users, but also between media, history, citizenship, and between teachers, students and institutions. The 'Emotional Map of Antifascist Memory Places' 35 is an example of 'how to write stories in geographies', sharing experiences through personal commentaries.

Another experience of great interest is the new 'geoblog' from the US Holocaust Memorial Museum's Genocide Prevention Mapping Initiatives, 
in partnership with Google Earth: World is Witness. The space aims at documenting and mapping genocide and related crimes against humanity that affected the populations of various countries around the world. By using Google Earth, the museum is mapping holocaust sites with historic content from its collections and developing high-impact initiatives such as that focused on the Darfur Conflict.

The geo-referenced documents are visible through the two new Google Earth's layers under the Global Awareness layer folder: 'USHMM: World is Witness' and 'Crisis in Darfur'. The layers are designed around the geoblog of USHMM and information goes from pictures taken in places of war, to links to podcasts, videos, and other content on the web site and at Facebook. 'World is Witness' geoblog also uses a Google Maps interface into the site to show the location related to the published comments.

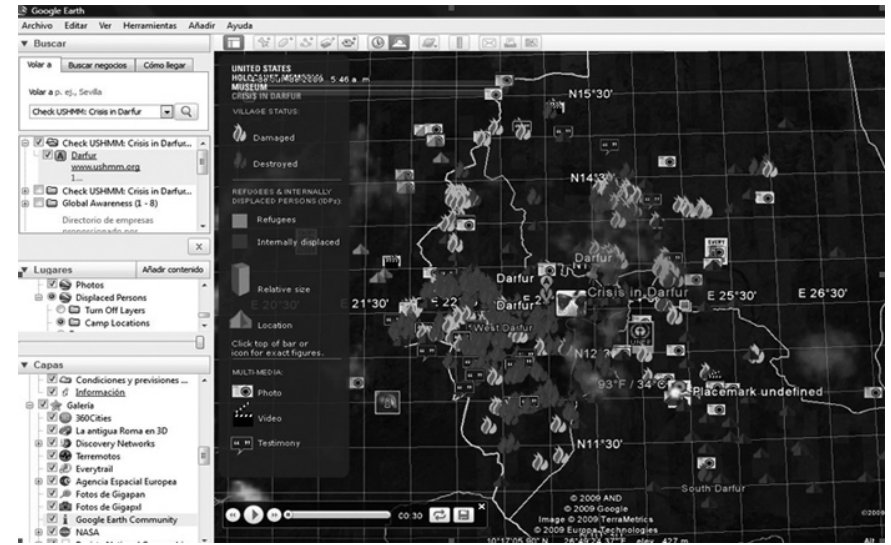

Figure 6. Genocide sites in Darfur region shown by a Google earth layer

Could this way of representation enhance virtual exhibitions? It probably depends on whether the exhibition's subject fits in a way of representation such as combination of historical and spatial events. For example, at the TU Delft collection: WatWasWaar ${ }^{36}$, the platform was designed for disclosing historicalgeographical information on the Netherlands to a wider audience by searching through time and place maps, images, and family history. There are also some widgets such as 'EXHIBIT' that combines geographical information with timelines ${ }^{37}$.

The creation of Placemark kml or kmz files could also create virtual visits on ad hoc basis. Applications such as Google Earth show KML files as webbrowsers display the HTML pages. Out of all these, an interesting example is, the KML file 'Art Museums 3D Tour', made available by Google, which enables to take a tour of $3 \mathrm{D}$ models featuring museums around the world. Models of the Museum of Modern Art of San Francisco, Museum of Contemporary Art of Chicago, the Smithsonian American Art Museum of Washington DC, the Metropolitan Museum of Art and the Guggenheim Museum of New York, the Rijksmuseum of Amsterdam, the Tate Modern and the National Gallery of London, the Louvre of Paris, the Guggenheim Museum of Bilbao and the Museo del Prado of Madrid are also located in the Google 3D Warehouse ${ }^{38}$.

\section{VIRTUAL WORLDS: THE LAST FRONTIER?}

Over the past five years, there have been a number of applications of 3D models and virtual worlds in real exhibits. There have been also some online applications, though they constituted simple tastes of potential uses. However, there is still a long way to go before fulfilling most expectations of virtual worlds in online exhibits.

There are many real exhibitions recreated within virtual worlds. One of these is an exhibition designed by the Museo Mart on 'La Parola nell'arte'. The exhibition was built by Style's editorial staff whereas the virtual layout was designed and set up by the architects of Second-Key (a team of developers, designers and creatives HiTech, specialised in the creation of communication events in Second Life). It occupied an area opened on January 2008 and was inaugurated by the avatar of the museum's director with the participation of a special guest from the New Museum of New York. Both avatars together led a visit through the Mart museum's art collection, explaining details about exhibit as well as presenting scientific projects. The video of such event was subsequently made available on YouTube ${ }^{39}$. Among the works built on Second Life, there are paintings, sculptures and installations by Nanni Balestrini, Jean-Michel Basquiat, Alighiero Boetti, Fortunato Depero, Marcel Duchamp, Giuseppe Chiari, Sabrina Mezzaqui, Gino Severini, Kurt Schwitters, Ben Vautier, and Andy Warhol.

Sometimes the use of a virtual environment enables user activities impossible in the real world, such as seeing exhibits from inaccessible points of view, observing details of an artifact or experimenting on it without causing any damage. With this goal in mind, the staff of the Exploratorium of San Francisco explored in 2006 the possibilities provided by Second Life. From these experiments it was born shortly after 'Splo', a virtual museum located in Second Life that offers the possibility of carrying out impossible experiments in reality such as flying through the solar system, scanning a body, changing gravity without falling down, as well as creating content and organising public events.

The Exploratorium virtual world in Second Life has a growing number of interactive exhibits, many of which would be impossible to recreate in the real museum in San Francisco. Staff members set up public events periodically and use the virtual word also for prototyping exhibitions and arranging 
provocative installations following the spirit of the Exploratorium. Although users are probably alone when experiencing the exhibitions, they are social in the online space by participating in virtual encounters, creating jam sessions, making movies with other friends, etc.

Another innovative project is the The Tech Museum of Innovation (opened in December of 2007 in Silicon Valley in San Jose) which aims at inspiring innovation in everyone and testing new exhibition contents. The best co-developed virtual designs are then used to set real exhibits at The Tech Museum. Since its opening in December 2007, 166 members have initiated 70 exhibition projects on The Tech Virtual website, and some of them have been selected to co-develop real exhibits in the real museum.

\section{CONCLUSIONS}

Almost a decade has passed by since reflection on virtual exhibits ${ }^{1}$ and those expectations have not been completely fulfilled. On the contrary, new technological developments have provided new potential tools to be applied in virtual exhibits as a way to disseminate displays that reflect intellectual initiatives and creations of memory institutions.

Although virtual exhibits were seen as complementary to real displays, they have become independent despite coming from the same source. It has become difficult to combine real and virtual exhibits as a common experience because of timing, distance and diversity of e-users. Due to this difficulty, only in a few cases they have managed to encourage visitors to come to the real exhibit, acting as basic content background for the real visit. Actually, most common cases reveal that the real and virtual exhibits have probably different audiences. Nevertheless, the virtual exhibit becomes an excellent way to disseminate real displays though in a different virtual format, which will have a long-lasting life. Therefore, virtual exhibits are in fact fixed resources once the real one is dismantled, and they could be used in different contexts (i.e., educational) and forms such as multimedia archives (i.e., content syndication RSS).

As mentioned earlier, virtual exhibits have their own new audience that does not normally coincide with the real auidence. Many applications expect the virtual audience's contribution or, in other words, that they take part in content creation. Web 2.0 tools have stimulated the public participation, which contributes with its own experiences, creativity and comments in exhibitions. It is still difficult to foresee how the social media will change types of virtual exhibit, though they are providing fresh ideas and contributions.

New technologies such as Flash or GoogleEarth have provided new potential narratives and aesthetics for virtual exhibits that can become powerful alternatives to real experiences. However, some of those applications involve a high investment that not all the museums can afford. Therefore, a clear distinction between high- and low-cost virtual exhibitions is also envisaged. A series of tools such as CMS and widgets have become easy solutions for low-cost online displays.

One of those powerful narratives and aesthetics comes also from virtual reality and recreation of $3 D$ models that have enjoyed so far a secondary role in online exhibits. When Second Life arouse, many cultural institutions thought it was an interesting environment for museum replica as well as displays, however there have not been many experiences in this sense. There is still a feeling that virtual reality will bring us to new frontiers, but one still has to wait...and see such exhibitions which may uses 4D, 5D and 7D models.

\section{ACKNOWLEDGEMENTS}

We wish to thank Laia Pujol (Aegean University) who reviewed an early draft of this paper and gave comments and useful suggestion.

\section{REFERENCES}

1. Carreras, C. Initial thoughts for setting up a virtual exhibition. ICHIM 2001, Milano, pp. 93-104.

2. http://oliba.uoc.edu/eivifor/.

3. Dutardre, Nadège. Public museums and public online real museums links? Ministry of Culture and Communication. Direction des Musées de France, 2003.

4. Aureum Opus. http://oliba.uoc.edu/aureum/.

5. Carreras, C. \& Munilla, G. Patrimonio digital, Barcelona, 2005.

6. Hein, G.E. Learning in the museum. London, 1998.

7. Hooper-Greenhill, E. (Ed.) Museum, media \& message. London, 1995.

8. Hooper-Greenhill, E. (Ed.) The educational role of the museum. London, 1996.

9. http://oliba.uoc.edu/carta/.

10. Virtual Leonardo. http://www.museoscienza.org/ leonardo/leonardovirtuale/default.asp/.

11. Treasures of nature. http://oliba.uoc.edu/ natura/.

12. Remembering Nagasaki. http://www.exploratorium. edu/nagasaki/mainn.html/.

13. Jasenovac 1941-1945 http://www.ushmm.org/ museum/ exhibit/online/jasenovac/.

14. Tunisian mosaics. http://oliba.uoc.edu/mosaic/. 
15. Carreras, C. \& Ferran, N. Preserving memories online: The exhibition memories of our childhood and the catalan history of immigration museum. En ICHIM 2004, Berlin, 2004. http://oliba.uoc. edu/nens/.

16. Corridos Sin Fronteras. http://www.corridos. org/.

17. Science Museum of London. http://www. sciencemuseum.org.uk/onlinestuff.aspx/.

18. Catalan Immigration History Museum. http:// www.mhic.net/.

19. Carreras, C. Voices: A virtual exhibition as alternative model to the forum 2004. DESIDOC J. Lib. Inf. Technol., July 2008, 28(4), 92-100. http://oliba.uoc.edu/veus/.

20. http://www.chin.gc.ca/English/Digital_ Content/2004Survey/index.html/.

21. Woman of Letters-Irene Nemirovsky and Suite Francaise. http://www.mjhnyc.org/irene/index. $\mathrm{html} /$.

22. Georges Seurat: The drawings. http://www.moma. org/interactives/ exhibitions/2007/seurat/.

23. Kirchner and the Berlin street. http://www.moma. org/interactives/exhibitions/2008/kirchner/.

24. Pictures from Traiguera. http://oliba.uoc.edu/ traiguera/.

25. Joomla 1.5! http://www.joomle.org/.

26. DNA ${ }^{26}$. http://oliba.uoc.edu/adn/.

27. Learning from Amazon and eBay. http://conference. archimuse.com/biblio/learning_from_amazon_ and_ebay_user_generated_material/.

28. http://www.flickr.com/photos/brooklyn_museum/ sets/72157594168613271/

29. Mitchell, W. E-topia: Urban life, Jim -- but not as we knew it. MIT Press, Cambridge, MA, 1999.

30. Take your time. http://www.moma.org/visit/calendar/ exhibitions/31/.

31. Samis, P. Who has the responsibility for saying what we see? Mashing up museum, artist, and visitor voices, on-site and online. In Museums and the Web 2008, edited by J. Trant and D. Bearman. Proceedings (CD-ROM)-Archives \& Museum Informatics, 31 March 2008, Toronto. http://www.archimuse.com/mw2008/papers/samis/ samis.html/.
32. Healey, W.L. The voice of the user: Where students and faculty go for information. http://www.outsellinc. $\mathrm{com} /$ (accessed on 4 November 2002).

33. Chan, S. Towards new metrics of success for online museum projects. In Museums and the Web 2008, edited by J. Trant and D. Bearman. Proceedings (CD-ROM)-Archives \& Museum Informatics, 31 March 2008, Toronto. http://www. archimuse.com/mw2008/papers/chan-metrics/ chan-metrics.html/.

34. Global interactive baroque. http://www.vam. ac.uk/microsites/baroque/interactive-map.html/.

35. Map of Antifascist memory places. http://memoria. acmos.net/.

36. WatWasWaar. http://watwaswaar.nl/.

37. EXHIBIT. http://www.simile-widgets.org/ exhibit/.

38. Google 3D Warehouse http://sketchup.google. com/3dwarehouse/.

39. YouTube. http://www.youtube.com/.

\section{About the Authors}

Dr César Carreras is a Senior Lecturer at the Department of Antiquity of the Autonomous University of Barcelona (UAB). He had been Lecturer of Humanities at the Open University of Catalonia (UOC) since 1997. He has a PhD in Ancient History from the University of Barcelona, another $\mathrm{PhD}$ in Archaeology from the University of Southampton (UK), and a Master in Computer Science Applied to Archaeology from the University of Southampton (UK). He has published numerous papers on classical archaeology and digital heritage.

Dr Federica Mancini is specialised in the evaluation of ICT applied to cultural heritage. After her PhD thesis titled 'Towards a participatory museum: Analysis of models and participatory experiences based on ICT for museums' in the Internet Interdisciplinary Institute (UOC) of Barcelona, she is collaborating with the Science and Technology Center of Prato (University of Florence). Her area of interest include: Analysis of new ways to communicate heritage for regional development, tourism, and public cultural participation. 